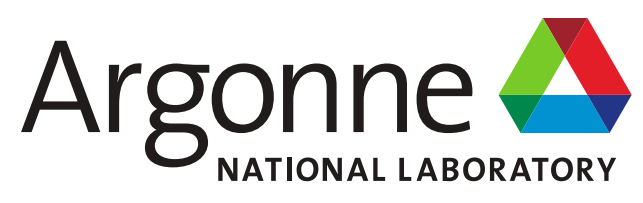

ANL/RTR/TM-21/19

\title{
University of Missouri Research Reactor LEU Fuel Element Flow Test Conceptual Design - Hydraulic Reactor Design Parameters
}

Nuclear Science \& Engineering Division 


\section{About Argonne National Laboratory}

Argonne is a U.S. Department of Energy laboratory managed by UChicago Argonne, LLC under contract DE-AC02-06CH11357. The Laboratory's main facility is outside Chicago, at 9700 South Cass Avenue, Argonne, Illinois 60439. For information about Argonne and its pioneering science and technology programs, see www.anl.gov.

\section{DOCUMENT AVAILABILITY}

Online Access: U.S. Department of Energy (DOE) reports produced after 1991 and a growing number of pre-1991 documents are available free at OSTI.GOV (http://www.osti.gov/), a service of the U.S. Dept. of Energy's Office of Scientific and Technical Information.

\section{Reports not in digital format may be purchased by the public from the National Technical Information Service (NTIS):}

U.S. Department of Commerce

National Technical Information Service

5301 Shawnee Rd

Alexandria, VA 22312

www.ntis.gov

Phone: (800) 553-NTIS (6847) or (703)

605-6000 Fax: (703) 605-6900

Email: orders@ntis.gov

\section{Reports not in digital format are available to DOE and DOE contractors from the Office of Scientific and Technical Information (OSTI):}

U.S. Department of Energy

Office of Scientific and Technical Information

P.O. Box 62

Oak Ridge, TN 37831-0062

www.osti.gov

Phone: (865) 576-8401

Fax: (865) 576-5728

Email: reports@osti.gov

Disclaimer

\section{Disclaimer}

This report was prepared as an account of work sponsored by an agency of the United States Government. Neither the United States Government nor any agency thereof, nor UChicago Argonne, LLC, nor any of their employees or officers, makes any warranty, express or implied, or assumes any legal liability or responsibility for the accuracy, completeness, or usefulness of any information, apparatus, product, or process disclosed, or represents that its use would not infringe privately owned rights. Reference herein to any specific commercial product, process, or service by trade name, trademark, manufacturer, or otherwise, does not necessarily constitute or imply its endorsement, recommendation, or favoring by the United States Government or any agency thereof. The views and opinions of document authors expressed herein do not necessarily state or reflect those of the United States Government or any agency thereof, Argonne National Laboratory, or UChicago Argonne, LLC. 


\section{University of Missouri Research Reactor LEU Fuel Element Flow Test Conceptual Design - Hydraulic Reactor Design Parameters}

prepared by

Guanyi Wang, Cezary Bojanowski, Andrew Hebden, Dhongik Yoon, and Erik Wilson Nuclear Science \& Engineering Division, Argonne National Laboratory

Leslie Foyto

University of Missouri-Columbia Research Reactor

August 2021 
(This page left intentionally blank) 


\section{Acronyms and Abbreviations}

FQ

DOE

HEU

HMFTF

LEU

LSSS

$\mathrm{M}^{3}$

MW

MURR $^{\circledR}$

NNSA

NQA

OSU

$\mathrm{RC}$

SAR

U-10Mo

USHPRR fuel qualification

U.S. Department of Energy

highly enriched uranium with $\geq 20$ wt.\% enrichment

Hydro-Mechanical Fuel Testing Facility

low-enriched uranium with $<20$ wt.\% enrichment

limiting safety system setting

NNSA Office of Material Management and Minimization

megawatts thermal

University of Missouri-Columbia Research Reactor

U.S. National Nuclear Security Administration

Nuclear Quality Assurance

Oregon State University

reactor conversion

Safety Analysis Report

uranium - 10 wt.\% molybdenum alloy fuel being developed as a monolithic metallic alloy fuel

U.S. high performance research reactor 


\section{Definition of Terms}

\begin{tabular}{|c|c|}
\hline Best estimate & $\begin{array}{l}\text { Parameter value that is determined with the best available methods } \\
\text { and/or models without including uncertainty. }\end{array}$ \\
\hline Bounding & $\begin{array}{l}\text { A parameter value that has been technically determined to not be } \\
\text { exceeded under given conditions, such as, for example, normal operating } \\
\text { conditions. }\end{array}$ \\
\hline Conservative & $\begin{array}{l}\text { Method, or resulting parameter value, that is not best estimate and } \\
\text { includes uncertainty or margin whether discretionary or due to } \\
\text { conservative assumptions. }\end{array}$ \\
\hline Fuel qualification & $\begin{array}{l}\text { The process of designing, conducting, and evaluating experiments to } \\
\text { ensure that the fuel is capable of performing without failure during } \\
\text { reactor operations up to reported performance limits. Fuel qualification } \\
\text { also includes measurements and reporting of fuel properties that can be } \\
\text { used in performance and safety modeling. }\end{array}$ \\
\hline $\begin{array}{l}\text { Limiting safety } \\
\text { system setting }\end{array}$ & $\begin{array}{l}\text { Limiting values for settings of the safety channels by which point } \\
\text { protective action must be initiated. The LSSSs are chosen so that } \\
\text { automatic protective action terminates the abnormal situation before a } \\
\text { safety limit is reached. The calculation of the LSSS shall include the } \\
\text { process uncertainty, the overall measurement uncertainty, and transient } \\
\text { phenomena of the process instrumentation. }\end{array}$ \\
\hline Nominal & Value of a parameter under normal operating conditions. \\
\hline $\begin{array}{l}\text { Prototypic } \\
\text { condition }\end{array}$ & $\begin{array}{l}\text { Conditions that are considered representative of normal operating } \\
\text { conditions and matching key aspects of the fuel design geometry. }\end{array}$ \\
\hline $\begin{array}{l}\text { Reactor design } \\
\text { parameter }\end{array}$ & $\begin{array}{l}\text { Best estimate value from reactor analysis used as a basis in experiment } \\
\text { design for fuel qualification and licensing tests. Each reactor stakeholder } \\
\text { in RC Pillar activities identifies and documents reactor design parameter } \\
\text { values. }\end{array}$ \\
\hline Regime appropriate & $\begin{array}{l}\text { A set of conditions representative of reactor operations for which the } \\
\text { value(s) does not have an impact on phenomena within a known range. } \\
\text { For example, irradiation-induced creep in U-10Mo fuel at USHPRR } \\
\text { operating conditions is not correlated to temperature, and therefore } \\
\text { temperatures at which thermally induced creep does not occur can be } \\
\text { referred to as "regime appropriate." }\end{array}$ \\
\hline Safety basis & $\begin{array}{l}\text { A SAR, referenced supporting information, and other regulatory } \\
\text { materials that provide the basis for safe operation of a reactor facility. }\end{array}$ \\
\hline Target test value & $\begin{array}{l}\text { The goal value based on a reactor design parameter to be achieved } \\
\text { during testing, such as during an irradiation experiment to support fuel } \\
\text { qualification or fuel demonstration. The FQ, or other, Pillar identifies and } \\
\text { documents target test values in collaboration with other Pillars based on } \\
\text { the reactor design parameters. }\end{array}$ \\
\hline
\end{tabular}

University of Missouri Research Reactor LEU Fuel Element Flow Test Conceptual Design - Hydraulic Reactor Design Parameters 


\section{Executive Summary}

The University of Missouri-Columbia Research Reactor (MURR ${ }^{\circledR}$ ) is one of five U.S. high performance research reactors (USHPRR), plus one critical facility, that actively collaborates with the National Nuclear Security Administration (NNSA) Material Management and Minimization( $\mathrm{M}^{3}$ ) Reactor Conversion Program to convert to the use of low-enriched uranium (LEU, < 20 wt.\% U-235) fuel. A new type of LEU fuel with very high density, based on an alloy of uranium and 10 weight percent molybdenum (U-10Mo), is expected to allow the conversion to LEU of USHPRR that have been found unable to be converted with previously qualified uranium silicide-aluminum ( $\left.\mathrm{U}_{3} \mathrm{Si}_{2}-\mathrm{Al}\right)$ dispersion fuel. MURR has been working with the USHPRR Reactor Conversion (RC) Pillar at Argonne National Laboratory to perform fuel element design and fuel cycle performance analyses, steady-state thermal hydraulics safety analyses, and accident safety analyses in preparation for the conversion of MURR and to support a preliminary Safety Analysis Report (SAR) for conversion to LEU fuel.

This work is performed in preparation for the flow test campaign that will be conducted by the USHPRR RC Pillar. The purpose of the hydraulic performance evaluation of the MURR LEU fuel element designed by the RC Pillar is to test a prototypic commercially fabricated LEU fuel element to determine whether any failure modes are observed or predicted in the fuel element, including significant deformations such as plate bending, twisting, or plate detachment from the side plate under selected safety-basis limits for reactor hydraulic conditions.

To support the design of the flow test for MURR LEU fuel element hydraulic performance evaluation, design parameters for hydraulic testing of the LEU fuel element are laid out in this report. These relate to design needs of the reactor and are, therefore, referred to as reactor design parameters since they do not take into account design margins required for the experimental test design and other purposes. The flow rate per element is calculated using a flow network approach to provide the target test value of inlet conditions for the flow test design. The fuel element geometry, in particular the fuel plate and the flow channel dimension, is reviewed and documented.

Fuel plate deflection could be induced by the hydrodynamic pressure differential caused by the disparity of the channel gap thicknesses of adjacent coolant channels. The pressure in the thinner channel is usually higher than that in the thicker channel, so the hydraulic pressure differential deflects the plate towards the thicker channel. For the MURR LEU fuel element, the plates with larger arc length (span) and less thickness are more limiting in term of flow-induced deflection.

One key dimension of the MURR flow test is the outer end channel gap thickness, which is related to the maximum displacement of the fuel plate under hydraulic force due to pressure differential. Both the nominal and the conservative (in term of flow-induced deflection) thickness of the outer end channel are determined based on the technical drawings, which is 0.0955 inch and 0.068 inch, respectively. In addition, the operating conditions of the proposed MURR LEU core, including the nominal coolant temperature, system pressure, and the coolant chemistry specification, are summarized to reference operating conditions for the flow test.

The flow rate per element calculated using the nominal end channel thickness is suggested as the target test value due to simplicity and conservatism, which is $468.8 \mathrm{gpm}$. In addition to the prototypic flow rate per element, uncertainty analysis is performed to estimate the upper bound for the flow rate per element. An uncertainty of $20.0 \%$ is suggested to obtain the upper bounding of flow rate per element from the nominal value, which leads to the maximum flow rate per element of $562.5 \mathrm{gpm}$. This $20.0 \%$ uncertainty is chosen by engineering judgment to conservatively envelop the core flow

University of Missouri Research Reactor LEU Fuel Element Flow Test Conceptual Design - Hydraulic Reactor Design Parameters 
uncertainty (4.7\%), element flow disparities due to end channel tolerance (1.3\%) and burnup-related channel reduction $(7.0 \%)$.

In summary, to support the flow test campaign that determines whether any failure modes are observed of the fuel element, two primary design parameters relevant to the hydraulic performance evaluation of MURR LEU fuel element are provided in this report. First is the geometry of the flow channel, especially the outer end channel gap thickness, which is related to the maximum hydraulic force (induced by pressure differential) on the fuel plate. Second is the flow rate per element, which is $468.8 \mathrm{gpm}$ and can be up to $20 \%$ higher if considering various uncertainties. This work provides information that will be used as a part of the design process for hydraulic evaluation, including flow testing a prototypic commercially fabricated LEU fuel element, and will be revised as needed. 


\section{Table of Contents}

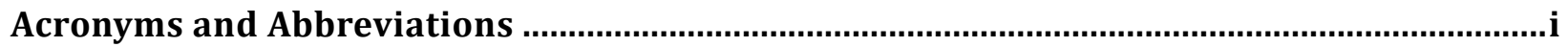

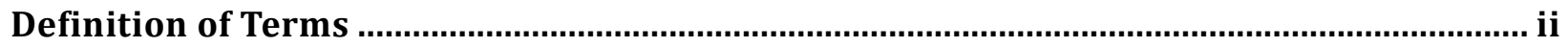

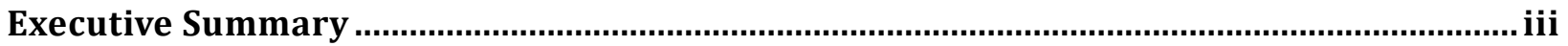

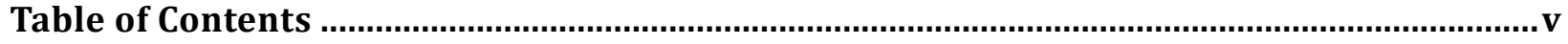

List of Figures

List of Tables ................................................................................................................................. vii

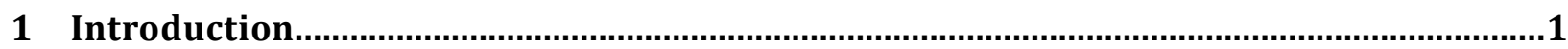

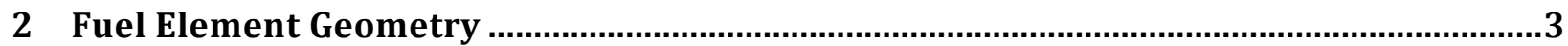

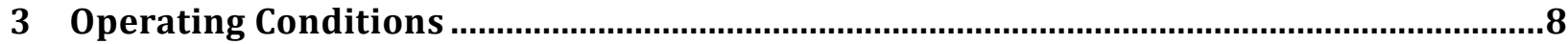

4 Target Test Value of Flow Rate

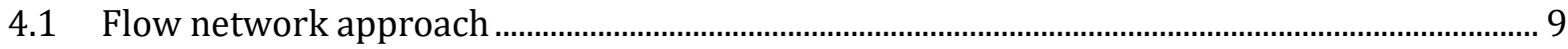

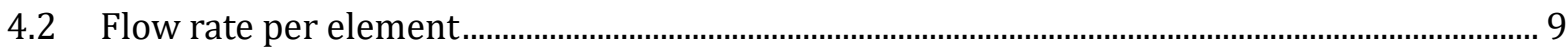

4.2.1 Effect of end channel gap thickness tolerance ..................................................................10

4.2.2 Effect of channel reduction due to burnup......................................................................11

4.2.3 Upper bound of flow rate per element................................................................................12

4.3 Channel flow distribution.......................................................................................................

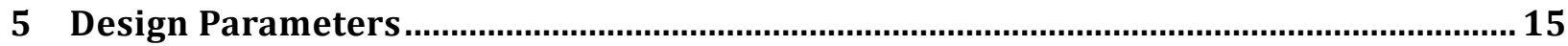

6 Summary

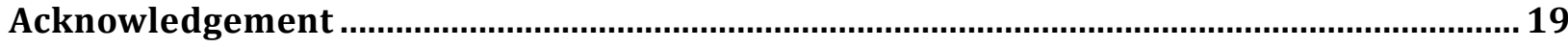

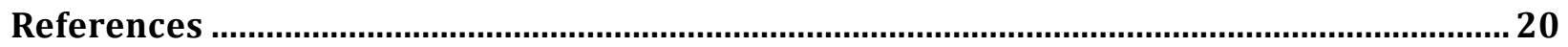




\section{List of Figures}

Figure 2.1. MURR core layout (a) and MURR LEU fuel element (b) and cross section (c) ...................... 3

Figure 2.2. Most limiting plate in terms of hydro-mechanical stability .......................................................... 5

Figure 2.3 Schematic side view of MURR LEU end channel gap............................................................... 6

Figure 2.4. Drawing of MURR LEU with end channel gap (fuel plate to roller) highlighted [3]............. 7 


\section{List of Tables}

Table 2.1. LEU Fuel Plate Nominal Values and Tolerances [1] …................................................................. 4

Table 2.2. MURR LEU End Channel Gap and Tolerances....................................................................................... 7

Table 3.1. MURR LEU Operating Design Parameters ................................................................................... 8

Table 4.1. Effect of End Channel Gap Thickness on Element Flow Distribution.........................................11

Table 4.2. Flow Rate Per Element Considering Channel Gap Reduction Due to Burnup........................12

Table 4.3. Target Test Value of Inlet Flow Rate and Upper Bounding based on 20\% Uncertainty.......13

Table 4.4. Channel Flow Velocity Distribution........................................................................................................14

Table 5.1. MURR LEU Hydraulic Reactor Design Parameters for Flow Test .............................................16 


\section{Introduction}

The University of Missouri Research Reactor (MURR ${ }^{\circledR}$ ) in Columbia, Missouri, is a multi-disciplinary research and education facility providing a broad range of analytical and irradiation services to the research community and the commercial sector. MURR is a $10 \mathrm{MW}$ light-water-cooled reactor using highly enriched uranium (HEU, $\geq 20$ wt.\% U-235) fuel [1].

MURR is one of five U.S. high performance research reactors (USHPRR), plus one critical facility, that actively collaborates with the National Nuclear Security Administration (NNSA) Material Management and Minimization $\left(\mathrm{M}^{3}\right)$ Reactor Conversion Program to convert to the use of lowenriched uranium (LEU, < 20 wt. \% U-235) fuel. A new type of LEU fuel with very high density, based on an alloy of uranium and 10 weight percent molybdenum (U-10Mo), is expected to allow the conversion to LEU of USHPRR [2] that have been found to be unable to be converted with previously qualified uranium silicide-aluminum $\left(\mathrm{U}_{3} \mathrm{Si}_{2}-\mathrm{Al}\right)$ dispersion fuel. A detailed description of the preliminary MURR LEU fuel element design can be found in [3].

The conversion of USHPRR, including MURR, is carried out through four technical pillars led by several national laboratories: the Fuel Qualification (FQ) Pillar (Idaho National Laboratory), Fuel Fabrication (FF) Pillar (Pacific Northwest National Laboratory), Reactor Conversion (RC) Pillar (Argonne National Laboratory or Argonne), and Cross-Cutting (CC) Pillar (Savannah River National Laboratory). Working with the RC Pillar, MURR has completed performance and safety analyses for prototypic equilibrium fuel cycle operations with the current HEU fuel and following conversion to the LEU fuel with a power uprate from $10 \mathrm{MW}$ to $12 \mathrm{MW}$ [1]. Performance and safety analyses have also been completed for HEU and the preliminary LEU fuel element design [3], which demonstrate satisfactory experimental performance and margins to safety following a major facility upgrade [4]. Recently, the planning and safety analysis for the sequence of transition cores in support of the conversion from HEU to equilibrium LEU operations have been finished [5].

This work is performed in preparation for the flow test campaign that will be conducted by the USHPRR RC Pillar. The purpose of the hydraulic performance evaluation of the MURR LEU fuel element designed by the RC Pillar is to test a prototypic commercially fabricated LEU fuel element to determine whether any failure modes are observed or predicted in the fuel element, including significant deformations such as plate bending, twisting, or plate detachment from the side plate under selected safety-basis limits for reactor flow conditions. The demonstration will be performed on prototypic LEU fuel elements by means of 1) out-of-pile flow test at OSU-HMFTF and 2) computational analysis. The flow tests are planned to be run beyond the operational limit to demonstrate the safety margin.

Fuel plate deflection can be induced during reactor operation by the hydrodynamic pressure differential caused by differences in the channel gap thickness of adjacent coolant channels, turbulent fluctuations in the flow, or both. Large flow-induced deflection of the fuel plate could lead to the reduction of coolant channel flow area, which results in fuel plate overheating. For adjacent coolant channels with different channel gap thicknesses, the pressure in the thinner channel is usually higher than that in the thicker channel, so the hydraulic pressure differential deflects the plate towards the thicker channel. For the MURR LEU fuel element, the plates with a larger arc length (span) and less thickness are more limiting in term of flow-induced deflection.

University of Missouri Research Reactor LEU Fuel Element Flow Test Conceptual Design - Hydraulic Reactor Design Parameters 
In the planned flow test, a single MURR LEU fuel element will be tested in the Hydro-Mechanical Fuel Testing Facility (HMFTF) at Oregon State University (OSU) to evaluate the hydro-mechanical stability of the fuel plates. HMFTF is a large-scale thermal-hydraulic separate-effects test facility operating in conformance with the American Society of Mechanical Engineers (ASME) Nuclear Quality Assurance (NQA-1) standard (ASME NQA-1b-2008 with 2009 Addenda) [6]. The facility allows for testing a wide range of elements if they fit into the 15-foot-tall test section. The HMFTF facility was designed to cover the flow and pressure operating conditions of all USHPRR as well as conditions required for fuel qualification. The range of operation of the loop covers flow rates ranging from 100 gpm to 1600 gpm and pressures of up to $475 \mathrm{psi}$. The testing loop is rated to $600 \mathrm{psig}$ and $460^{\circ} \mathrm{F}$. The configuration of the loop allows for up- and down-flows through the test section.

To support the conceptual design of the flow test for MURR LEU fuel element, design parameters for hydraulic testing of the LEU fuel element are laid out in this report. These relate to design needs of the reactor and are, therefore, referred to as reactor design parameters since they do not take into account design margins required for the experimental test design and other purposes. Normal operating conditions of MURR including system pressure, coolant temperature, and total core flow rate are listed to provide references for the flow test conceptual design. Flow rates per element are estimated based on the flow network analysis, which provides the target test value of the inlet condition for the flow test. 


\section{Fuel Element Geometry}

The cross-sectional view of the layout of MURR core is shown in Figure 2.1 (a). A total of eight fuel elements are in the annular pressure vessel made of aluminum. MURR LEU fuel element consists of 23 arc-shaped fuel plates, as shown in Figure 2.1 (b). The arc angle of these fuel plates is about $45^{\circ}$.

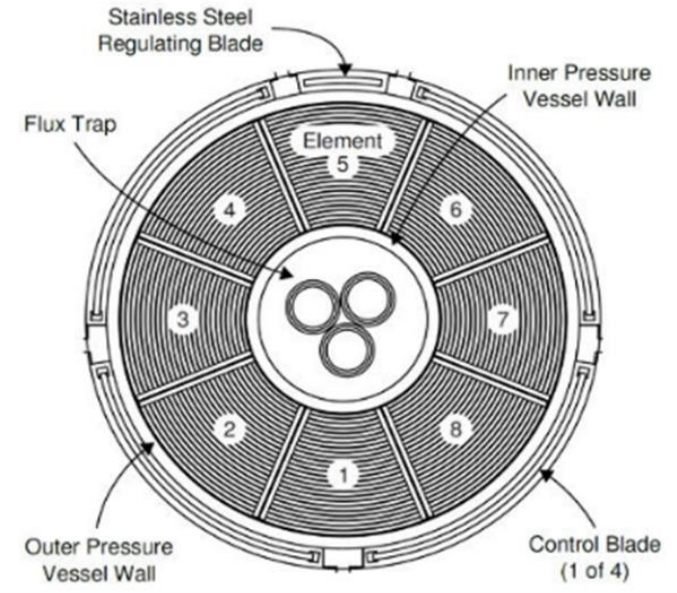

(a)

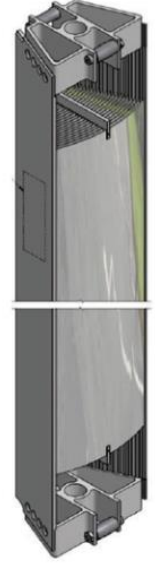

(b)

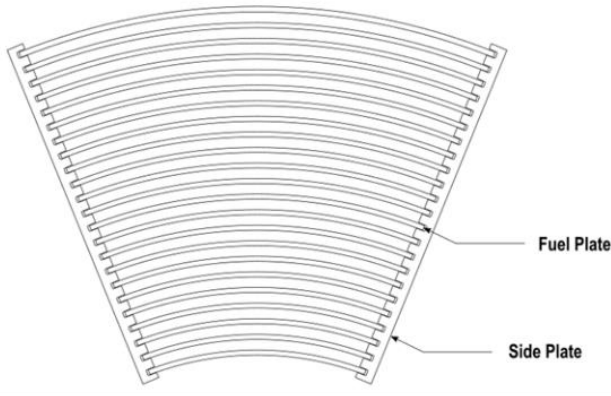

(c)

Figure 2.1. MURR core layout (a) and MURR LEU fuel element (b) and cross section (c)

The nominal values of the LEU fuel plate dimension and tolerances are listed in Table 2.1. The deflection magnitude of the fuel plate at a given flow rate is affected by three fuel plate design parameters: the channel gap thickness that affects the pressure differential on the two sides of the fuel plate, and the arc length (span) and thickness of the fuel plate that affect its stiffness. When coolant flow through the fuel element and the dimension of two adjacent channels of a fuel plate differ by design or tolerance, there will be a pressure differential on the fuel plate that tends to deflect the plate towards the channel with lower pressure; that is the thicker channel.

As shown in Figure 2.2, the most limiting plates in terms of hydro-mechanical stability for the MURR LEU fuel element could be plate 22 or 23, because these two have the largest arc length. The thickness of plate 22 is 0.044 inch while for plate 23 is 0.049 inch. Therefore, both plates may be the limiting ones. 
Table 2.1. LEU Fuel Plate Nominal Values and Tolerances [1]

\begin{tabular}{|c|c|c|}
\hline Fuel Plate Dimension & Location & $\begin{array}{c}\text { Nominal Value and } \\
\text { Tolerance }\end{array}$ \\
\hline \multirow{5}{*}{ Fuel Core Thickness } & Plate 1 & $0.009 \pm 0.001$ inch \\
\hline & Plate 2 & $0.012 \pm 0.001 \mathrm{inch}$ \\
\hline & Plate 3 & $0.016 \pm 0.001 \mathrm{inch}$ \\
\hline & Plate 4-22 & $0.020 \pm 0.001 \mathrm{inch}$ \\
\hline & Plate 23 & $0.017 \pm 0.001 \mathrm{inch}$ \\
\hline U-235 Content & All Plates & $19.75 \pm 0.20$ wt. $\%$ \\
\hline Molybdenum Content & All Plates & $10 \pm 1$ wt. $\%$ \\
\hline Zirconium Interlayer & All Plates & $0.001 \pm 0.0005$ inch \\
\hline \multirow{5}{*}{$\begin{array}{l}\text { AA6061 Cladding } \\
\text { Thickness }\end{array}$} & Plate 1 & $0.0165 \pm 0.001$ inch \\
\hline & Plate 2 & $0.015 \pm 0.001 \mathrm{inch}$ \\
\hline & Plate 3 & $0.013 \pm 0.001 \mathrm{inch}$ \\
\hline & Plate 4-22 & $0.011 \pm 0.001 \mathrm{inch}$ \\
\hline & Plate 23 & $0.015 \pm 0.001 \mathrm{inch}$ \\
\hline \multirow{2}{*}{ Plate Thickness } & Plate 1-22 & $0.044 \pm 0.002 \mathrm{inch}$ \\
\hline & Plate 23 & $0.049 \pm 0.002$ inch \\
\hline \multirow{5}{*}{ Channel Gap Thickness ${ }^{b}$} & Channel 1 & $0.0955(0.067$ to 0.123$) \mathrm{inch}$ \\
\hline & Channel 2-5 & $0.093 \pm 0.008$ inch \\
\hline & Channel 6-19 & $0.092 \pm 0.008 \mathrm{inch}$ \\
\hline & Channel 20-23 & $0.093 \pm 0.008$ inch \\
\hline & Channel 24 & $0.0955(0.068$ to 0.124$) \mathrm{inch}$ \\
\hline
\end{tabular}

a The measured point minimum AA6061 cladding thickness ("point minclad") by ultrasonic probe inspection can be 0.0095 inches with a bulk minimum AA6061 cladding thickness ("bulk minclad") no less than 0.0107 inches. The terms "point minclad" and "bulk minclad" are defined in [7]

b For channel 1 and 24, the dimension shown here is between the pressure vessel wall and the surface of the plate, whereas in [1], the dimension displayed for channel 1 and 24 is from the roller bounding edge to the surface of the plate, so the value displayed in this table for channel 1 and 24 is 0.015 inch larger than that in [1]. 


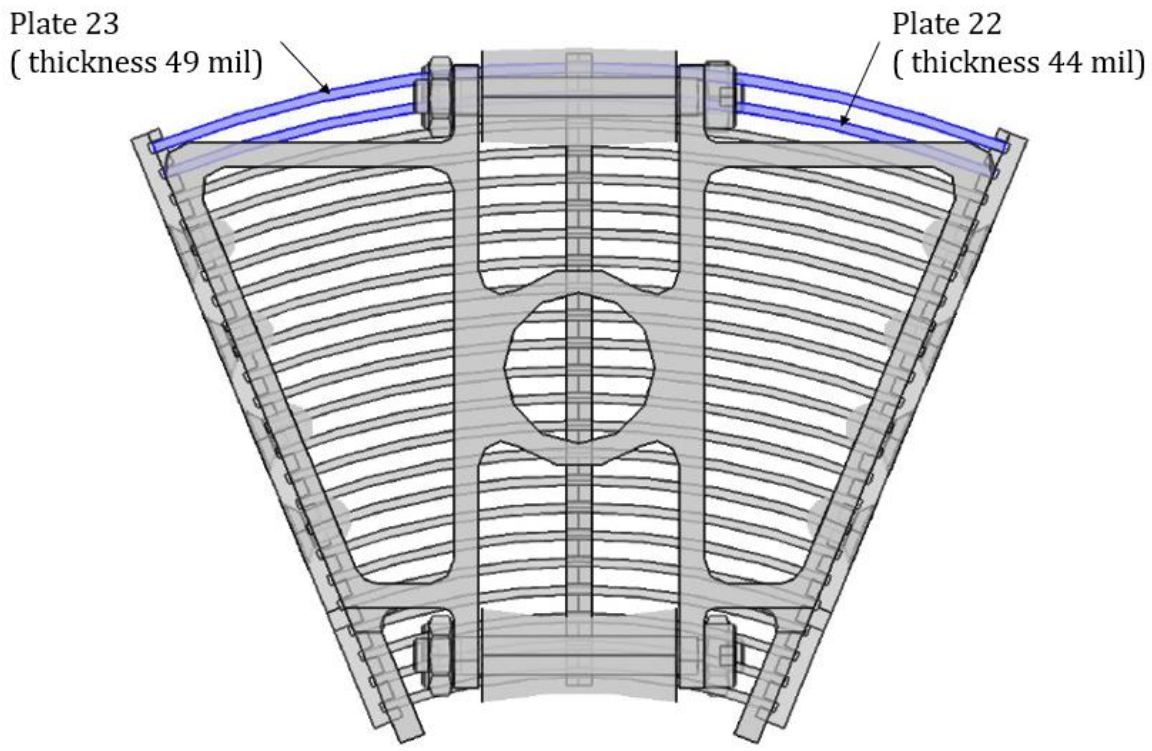

Figure 2.2. Most limiting plate in terms of hydro-mechanical stability

A basket (test vehicle) needs to be designed to fit the MURR LEU fuel element into the test section of HMFTF, which is a 6 inch pipe. To ensure that the flow test result is representative of the prototypic condition, the dimensions of the end channels (channel 1 and 24) should be considered in the basket design. As shown in Table 2.1, the tolerance of channels 1 and 24 is much larger than that of the inner channels. The thickness of channels 1 and 24 consists of two parts: 1) the distance from fuel plates (plate 1 or 23) to the roller bounding surfaces (inner or outer), and 2) the distance from the roller bounding surfaces to the pressure vessel walls, which are schematically indicated in Figure 2.3 as A and B, respectively. Note that dimension A in Figure 2.3 is determined by the fabrication of the fuel element, while dimension B in Figure 2.3 is determined by the position of the fuel element in the pressure vessel.

Figure 2.4 is from the technical drawing of MURR LEU fuel element [3], which indicates the distance from fuel plates (plate 1 or 23) to the roller bounding surfaces is 0.0805 inch for nominal dimension. In addition to the nominal value, the drawing also specifies the lower and upper limit for the distance from fuel plates (plate 1 or 23) to the roller bounding surfaces, which is 0.068 inch and 0.094 inch for channel 24, and 0.067 inch and 0.093 inch for channel 1 . Note that this dimension is determined by the fuel element manufacturing. The second part of the end channel gap, the distance from the roller bounding surfaces to the pressure vessel walls (dimension B in Figure 2.3), depends on the positioning of the fuel element in the pressure vessel. The distance between the inner and outer wall of the pressure vessel is 0.030 inch larger than the distance between the inner and outer roller bounding surfaces of the fuel element. For the nominal condition (Figure 2.3 (a)), this 0.030 inch difference will contribute equally to the dimension of channels 1 and 24, namely 0.015 inch for each channel, which leads to the nominal end channel gap of 0.0955 inch. For the extreme case (Figure 2.3 (b)), the roller bounding surface could contact the outer wall and the additional 0.030 inch all contribute to the inner wall, which results in the minimum channel 24 dimension $(0.068 \mathrm{inch})$ and maximum channel 1 dimension (0.123 inch). Also, minimum channel 1 dimension and maximum channel 24 dimension occurs when the roller bounding surface contacts the inner wall of the pressure vessel. A summary of these values is provided in Table 2.2. 
The overall fuel element length is 32.5 inch. The fuel plate length is 25.5 inch, which includes the active fuel length of 24 inch [3]. The inner and outer radii of the pressure vessel wall are 2.66 and 5.90 inch, respectively. The nominal gap between the side plates of two adjacent elements when placed in the reactor pressure vessel is 0.040 inch.

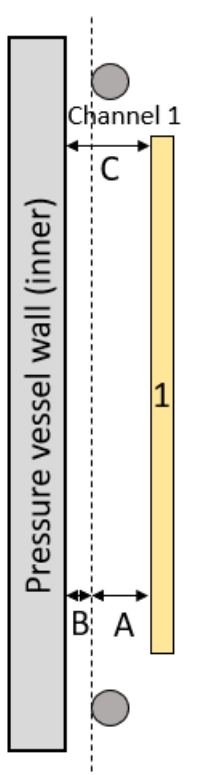

Fuel plate $\times 23$

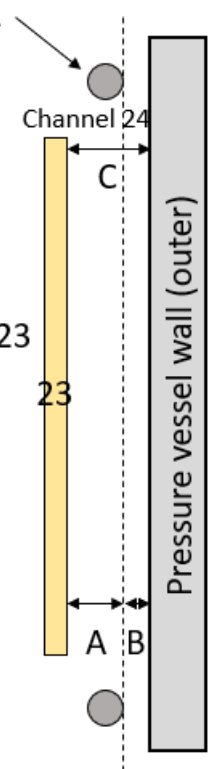

(a)
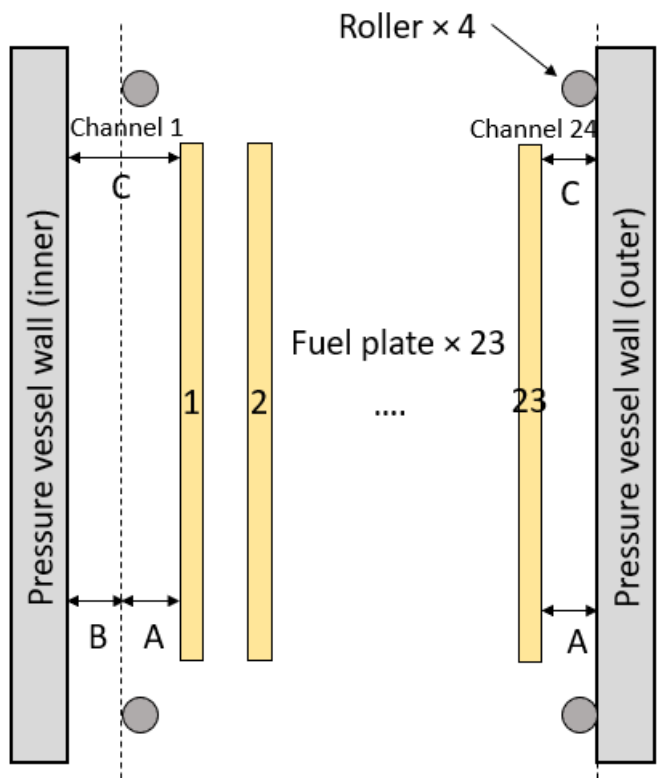

(b)

Figure 2.3 Schematic side view of MURR LEU end channel gap

(a) fuel element centered between inner and outer pressure vessel wall (b) fuel element contacted the outer wall 


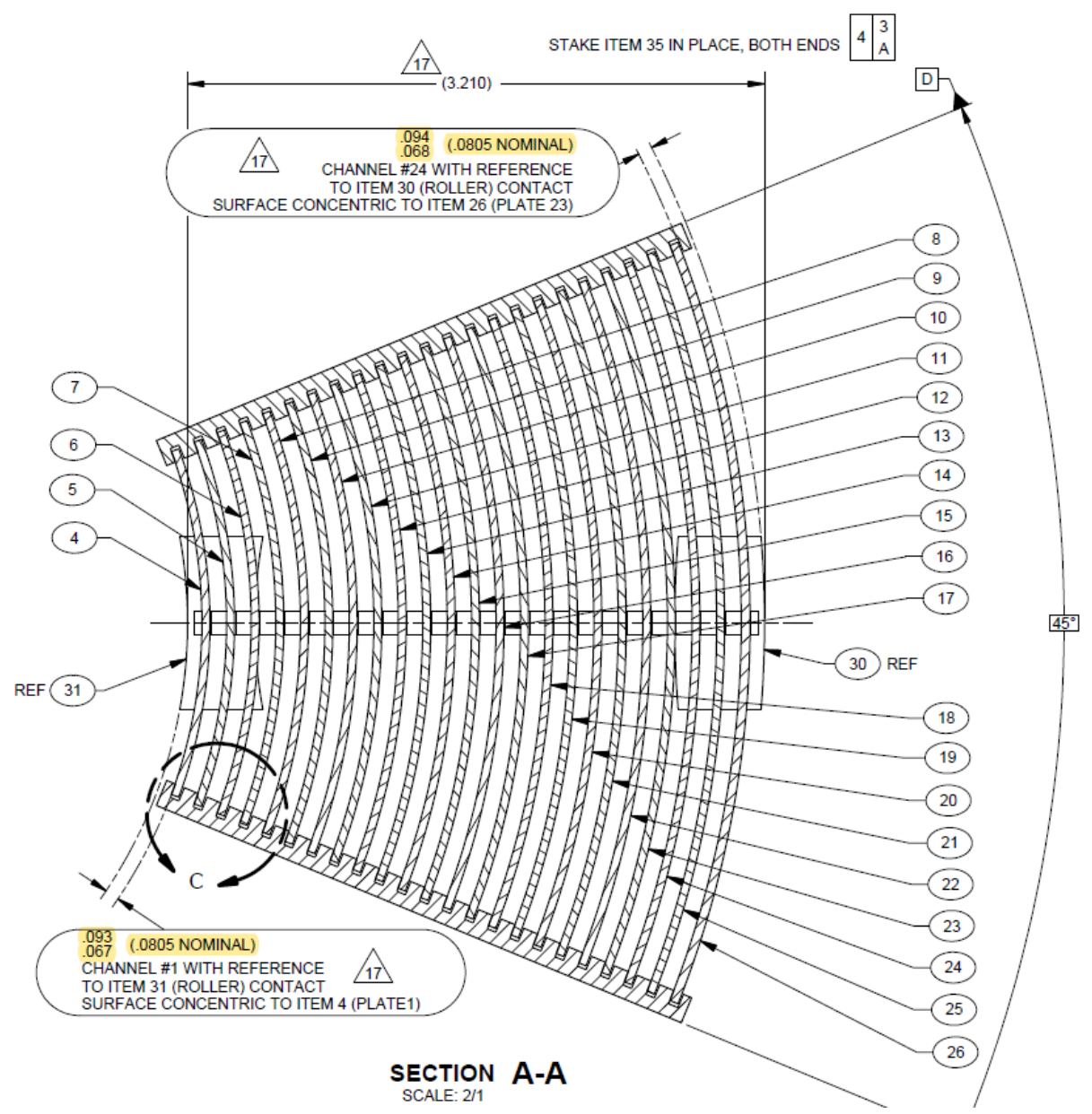

Figure 2.4. Drawing of MURR LEU with end channel gap (fuel plate to roller) highlighted [3]

Table 2.2. MURR LEU End Channel Gap and Tolerances

\begin{tabular}{|c|c|c|c|c|c|}
\hline Dimension of & $\begin{array}{l}\text { Tolerance } \\
\text { source }\end{array}$ & Channel & $\begin{array}{l}\text { Nominal } \\
\text { thickness } \\
\text { (inch) }\end{array}$ & $\begin{array}{c}\text { Minimum } \\
\text { thickness } \\
\text { (inch) }\end{array}$ & $\begin{array}{c}\text { Maximum } \\
\text { thickness } \\
\text { (inch) }\end{array}$ \\
\hline \multirow{2}{*}{ A. Plate to roller } & \multirow{2}{*}{$\begin{array}{l}\text { Fuel element } \\
\text { manufacture }\end{array}$} & Channel 1 & 0.0805 & 0.067 & 0.093 \\
\hline & & Channel 24 & 0.0805 & 0.068 & 0.094 \\
\hline \multirow{2}{*}{ B. Roller to wall } & \multirow{2}{*}{$\begin{array}{c}\text { Fuel element } \\
\text { positioning }\end{array}$} & Channel 1 & 0.015 & 0 & 0.030 \\
\hline & & Channel 24 & 0.015 & 0 & 0.030 \\
\hline \multirow{2}{*}{$\begin{array}{l}\text { C. Channel gap } \\
\text { total }(1+2)\end{array}$} & \multirow{2}{*}{ Both } & Channel 1 & 0.0955 & 0.067 & 0.123 \\
\hline & & Channel 24 & 0.0955 & 0.068 & 0.124 \\
\hline
\end{tabular}




\section{Operating Conditions}

The MURR LEU preliminary Safety Analysis Report (SAR) [1], accident analyses report of MURR for LEU conversion [8], MURR irradiation demonstration element design parameter report [9], and MURR SAR [10] have been reviewed to collect the reactor design parameters relevant to the flow test. The results are summarized in Table 3.1.

MURR has a downward flow in the core, and the prototypic flow rate is $3750 \mathrm{gpm}$ [1], which will be used as a basis for the flow rate per element calculations in the next section. The pressurizer pressure is 66 psig. The nominal inlet and outlet coolant temperature is $49^{\circ} \mathrm{C}$ and $61{ }^{\circ} \mathrm{C}$ [1], respectively, while the maximum fuel centerline temperature is $149^{\circ} \mathrm{C}$ [9]. Note that the maximum temperature at the fuel centerline and cladding surface shown in Table 3.1 were calculated by assuming a flow rate of $3800 \mathrm{gpm}$ and an inlet temperature of $50{ }^{\circ} \mathrm{C}\left(122^{\circ} \mathrm{F}\right)$. While these conditions are slightly different from the prototypic core flow rate and coolant inlet temperature assumed here, this will have only a small effect on the temperature predictions. It should also be noted that the fuel centerline temperature and cladding surface temperature are not expected to affect the plate deflection analysis. As mentioned in the introduction, the coolant is light water, with the pH maintained between 5 to 6 . The nominal reactor power is $12 \mathrm{MW}$ for LEU operations, while the power at limiting safety system setting (LSSS) is $15 \mathrm{MW}$. These hydraulic reactor design parameters, including pressure, temperature, and coolant chemistry information, provide references for the flow test operation.

Table 3.1. MURR LEU Operating Design Parameters

\begin{tabular}{|c|c|c|}
\hline Parameter & Value & Reference \\
\hline $\begin{array}{l}\text { Flow Rate } \\
\text { Prototypic } \\
\text { LSSS }\end{array}$ & $\begin{array}{l}3750 \mathrm{gpm} \\
3300 \mathrm{gpm}\end{array}$ & $\begin{array}{c}\text { [1] page } 3-2,4-14 \\
\text { [1] page } 4-87\end{array}$ \\
\hline $\begin{array}{l}\text { Coolant Temperature Increase } \\
\text { At Prototypic Flow }\end{array}$ & $12^{\circ} \mathrm{C}\left(21^{\circ} \mathrm{F}\right)$ & [1] page 6-2 \\
\hline $\begin{array}{l}\text { Primary System Pressure } \\
\text { Normal Operating Band } \\
\text { LSSS }\end{array}$ & $\begin{array}{c}\text { 60-66 psig } \\
60.7 \text { psig ( } 75 \text { psia) }\end{array}$ & $\begin{array}{c}\text { [8] Table } 3.1 \\
\text { [8] page } 14\end{array}$ \\
\hline $\begin{array}{l}\text { Coolant Outlet Temperature } \\
\text { Nominal }\end{array}$ & $61^{\circ} \mathrm{C}\left(141^{\circ} \mathrm{F}\right)$ & [1] page 6-2 \\
\hline $\begin{array}{l}\text { Coolant Inlet Temperature } \\
\text { Nominal } \\
\text { LSSS }\end{array}$ & $\begin{array}{l}49^{\circ} \mathrm{C}\left(120^{\circ} \mathrm{F}\right) \\
63^{\circ} \mathrm{C}\left(145^{\circ} \mathrm{F}\right)\end{array}$ & [1] page 6-2 \\
\hline $\begin{array}{l}\text { Maximum Temperature }^{a} \\
\text { Cladding Surface } \\
\text { Fuel Centerline }\end{array}$ & $\begin{array}{l}115^{\circ} \mathrm{C} \\
149^{\circ} \mathrm{C}\end{array}$ & [9] Table 4-2 \\
\hline $\begin{array}{l}\text { Water Chemistry } \\
\text { pH }\end{array}$ & $5-6$ & [10] Section 16.1.4 \\
\hline $\begin{array}{l}\text { Power } \\
\text { Nominal } \\
\text { LSSS }\end{array}$ & $\begin{array}{l}12 \mathrm{MW} \\
15 \mathrm{MW}\end{array}$ & $\begin{array}{l}\text { [1] page } 1-1 \\
\text { [1] page } 4-87\end{array}$ \\
\hline
\end{tabular}




\section{Target Test Value of Flow Rate}

In the planned MURR LEU flow test, a single fuel element will be tested in HMFTF. It is critical to ensure that the flow test for one element is representative of the prototypic MURR operating conditions. Therefore, the inlet flow rate for the flow test should be properly determined. In this section, the flow rate per element will be estimated based on the dimensions of the plates that are most limiting to flow-induced deflection and the adjacent coolant channels as described in Section 2 and the operating conditions summarized in Section 3, which will provide the target test value of the inlet flow rate for the flow test.

\subsection{Flow network approach}

The flow network approach is used to estimate the flow rate per element, which is a method based on the conservation of mass and pressure-drop balance. For parallel channels, the sum of mass flow rates in each channel should equal the total inlet mass flow rate:

$$
\sum_{i=1}^{k} n_{i} m_{i}=m_{t o t}
$$

where $n_{i}$ is the number fo channel type i, $m_{i}$ represents the mass flow rate of channel type i, and $m_{\text {tot }}$ is the total mass flow rate of the core. The pressure-drop balance can be expressed as:

$$
d p_{1}=d p_{2}=\cdots=d p_{i}
$$

where $d p_{k}$ is the pressure drop in channel $\mathrm{i}$, which can be calculated using:

$$
d p_{i}=\frac{\rho v_{i}^{2}}{2}\left(\frac{f_{i} L}{D_{h, i}}\right)
$$

$v_{i}$ is the flow velocity, $\rho$ is the coolant density. $L$ and $D_{h, i}$ are the length and hydraulic diameter of the channel, respectively, and $f_{i}$ is the friction factor. The friction factor is calculated using the explicit form [11] of the Colebrook-White equation [12]:

$$
f=\left\{-2 \log \left[\frac{\varepsilon}{3.7 D_{h}}+\frac{5.02}{R e} \log \left(\frac{\varepsilon}{3.7 D_{h}}+\frac{13}{R e}\right)\right]\right\}^{-2}
$$

The surface roughness $\varepsilon$ is $6.30 \times 10^{-5} \mathrm{inch}$, which is the maximum allowed surface roughness of each fuel plate of MURR [13]. With the known channel dimensions and number, the flow rate for each channel can be calculated using Eq. (4.1) to (4.4).

\subsection{Flow rate per element}

In this section, the flow rate per element is calculated using the flow network method, and the effects of end channel gap thickness tolerance and channel gap reduction due to burnup are evaluated. To calculate the flow rate per element, each element is considered as a 'channel' in the flow network model, and the hydraulic diameter used in Eq. (4.3) and (4.4) is calculated using the total flow area 
and wetted perimeter of an element. This simplified approach is also used in the previous safety analyses of MURR [5, 8] for estimating the core flow rate of the analyses.

Assuming all fuel elements have the same channel gap thickness, the flow will be evenly distributed, and the flow rate per element can be calculated by dividing the total flow of $3750 \mathrm{gpm}$ by the number of fuel elements (8), which is $468.75 \mathrm{gpm}$ (rounded to $468.8 \mathrm{gpm}$ throughout this report). However, the tolerance of the end channel gap thickness is relatively large, and thus, its effect on flow rate per element uncertainty should be evaluated, which is discussed in Section 4.2.1. In addition, the burnuprelated channel reduction leads to flow disparity between elements. For the element with high burnup, the channel gap thickness decreases and less coolant flows through it due to the higher friction, while for the fresh element the flow rate would be higher. The effect of channel reduction due to burnup is discussed in Section 4.2.2.

\subsubsection{Effect of end channel gap thickness tolerance}

As discussed in Section 2 (Table 2.2), the nominal value of end channel gap thickness (channel 1 and 24) is 0.0955 inch, which is close to the internal channel gap of 0.093 inch on the other side of the adjacent plate. For the nominal channel gap thicknesses, the pressure differential between channels should be small, and the resulting fuel plate deflection is expected to be less limiting than in the case when the channel gaps are at their extreme dimensions. The tolerance of the end channel gap is 0.028 inch for Channels 1 and 24. Thus, the channel size disparity between the end channel (channel 1 or 24 ) and the adjacent internal channel (channel 2 or 23) could be large. Under these conditions, plate 23 is expected to have a larger deflection compared to plate 1 . Because the arc length of plate 23 ( $4.338 \mathrm{inch}$ ) is more than two times larger than that of plate 1 (1.980 inch), yet the thickness of plate 23 ( $0.049 \mathrm{inch})$ is only $9 \%$ more than that of plate $1(0.044 \mathrm{inch})$. Therefore, the dimension of channel 24 is a primary value to be considered in the flow test basket design.

The channel 23 gap thickness is nominally 0.093 inch. If the gap thickness of channel 24 is less than 0.093 inch, the velocity in channel 24 will be lower and the static pressure will be higher than that of channel 23. As a result, the pressure differential applied on plate 23 is inward (towards the center of the core). Conversely, if the gap thickness of channel 24 is larger than 0.093 inch, the pressure differential will be acting outward. Given the arc shape of plate 23, the inward force is more limiting. This is because for that direction of load, snap-through buckling of the plate may occur at sufficiently high pressure, which is observed in previous experiments for curved plates [14] [15]. Therefore, the minimum Channel 24 gap is targeted in the flow test basket design.

As detailed in Section 2 (Table 2.2), the channel 24 gap consists of two parts: one is the distance from plate 23 to the outer roller bounding surface of the element, and the other is the distance from the outer roller bounding surface to the pressure vessel outer wall. The distance from the plate to the roller is determined by the fabrication of the fuel element and cannot be adjusted by the basket design for the flow test, so for the purpose of this analysis it was assumed that this distance will be the nominal value of 0.0805 inch. The distance from the roller bounding surface to the wall depends on the fuel element positioning tolerance $(0.030 \mathrm{inch})$ in the pressure vessel, which can be adjusted by basket design for the flow test. Since the minimum channel 24 gap is targeted to obtain the pressure differential acting inward, the basket should be designed to have the outer roller bounding surface touching against the basket wall, so the roller to wall distance is zero and the channel 24 gap would be 0.0805 inch (min 0.068 inch, max 0.094 inch).

By varying the end channel gap thickness within the tolerance and using the flow network to calculate the flow distribution, the effect of end channel gap thickness on flow distribution can be estimated,

University of Missouri Research Reactor LEU Fuel Element Flow Test Conceptual Design - Hydraulic Reactor Design Parameters 
as shown in Table 4.1. Fuel elements are represented in pairs in the flow network model. The elements in core positions 1 and 5 (refer to Figure 2.1 (a) for element location in the core), referred to here as elements X1 and X5, respectively, are assumed to have the various end channel gap thicknesses for different cases, while the other six elements are assumed to have the nominal end channel gap thickness (0.0955 inch). All elements are assumed to be fresh, and the burnup-related channel gap reduction is not considered here. Therefore, the selection of fuel element pairs (e.g., X1, $\mathrm{X} 5$ or X4, X8) for varying end channel gap thickness does not affect the results, and the reason for selecting elements X1 and X5 is to be consistent with the following section, in which the burnup is considered and elements X1 and X5 are of interest. For the Case 'Nominal', all fuel elements, including $\mathrm{X} 1$ and X5, have the nominal end channel gap, so the flow rate per element is the same for all elements. The Case 'Outer nominal' means the outer roller touches the wall, while the distance from the plate to the roller bounding surface is still at the nominal value (0.0805), which leads to 0.0805 inch of outer end channel gap thickness and 0.1105 inch of inner end channel gap thickness. The predicted flow rate per element, in this case, is $465.5 \mathrm{gpm}$, which is $0.7 \%$ lower than for the 'Nominal' Case (468.8 gpm). To explore the maximum effect of end channel gap thickness on flow distribution, Case 'Outer min' has the outer end channel at the minimum value of $0.068 \mathrm{inch}$ and the inner end channel at the maximum value of 0.123 inch. The Case 'Outer max' has the inner end channel at the minimum value of 0.067 inch and the outer end channel at the maximum value of 0.124 inch. The predicted flow rate per element for these two extreme cases is $\sim \pm 1.3 \%$ different from the Case 'Nominal'. Therefore, the effect of changing end channel gap thickness within the manufacturing and assembly tolerances on the element flow distribution is insignificant.

Table 4.1. Effect of End Channel Gap Thickness on Element Flow Distribution

\begin{tabular}{|c|c|c|c|c|c|c|}
\hline \multirow{2}{*}{ Case } & \multicolumn{2}{|c|}{$\begin{array}{c}\text { End channel gap of X1 and } \\
\text { X5 (inch) }\end{array}$} & \multicolumn{4}{|c|}{ Flow rate per element (gpm) } \\
\cline { 2 - 7 } & Channel 1 & Channel 24 & $\mathrm{X1}^{\mathrm{a}}, \mathrm{X}^{\mathrm{a}}$ & $\mathrm{X3}^{\mathrm{a}}, \mathrm{X7}^{\mathrm{a}}$ & $\mathrm{X}^{\mathrm{a}}, \mathrm{X6}^{\mathrm{a}}$ & $\mathrm{X}^{\mathrm{a}}, \mathrm{X}^{\mathrm{a}}$ \\
\hline Nominal & 0.0955 & 0.0955 & 468.8 & 468.8 & 468.8 & 468.8 \\
\hline Outer nominal & 0.1105 & 0.0805 & 465.5 & 469.8 & 469.8 & 469.8 \\
\hline Outer min & 0.123 & 0.068 & 462.8 & 470.7 & 470.7 & 470.7 \\
\hline Outer max & 0.067 & 0.124 & 474.9 & 466.7 & 466.7 & 466.7 \\
\hline
\end{tabular}

a Refer to Figure 2.1 (a) for element location in the core.

\subsubsection{Effect of channel reduction due to burnup}

In MURR LEU safety analysis [5, 8], a maximum of 0.008 inch channel gap reduction $(0.004$ inch for end channels) is used at the maximum burnup (180 MWd), and a linear relation between burnup and the channel gap reduction is assumed. The approach of 0.008 inch maximum channel gap reduction and linear relation with burnup is followed in this work.

The flow rate per element considering channel gap reduction due to burnup is presented in Table 4.2. The fuel element burnup amount used for the calculations presented here is assumed following the analysis for the MURR LEU equilibrium core [5, 8]. Since the fuel elements of MURR are loaded in pairs, each pair of elements will have the same burnup level. The elements X4 and X8 have the maximum burnup of $180 \mathrm{MWd}$ and the minimum flow area due to the 0.008 inch channel gap thickness reduction. As a result, the flow rate per element is the lowest compared to the other three pairs, which is the most limiting location in terms of cooling capability. However, from the structural aspect of the fuel plate, the one with maximum flow rate is more limiting, as a higher flow rate leads to a larger pressure differential that results in a higher hydraulic load to the plate. Therefore, the flow rate for the fresh elements (X1 and X5) is of interest in the flow test. By comparing the flow rate of 
fresh elements (X1 and X5) for different cases in Table 4.2, the variance of predicted flow rate per element is less than $\pm 1.3 \%$, which means the effect of changing end channel gap within tolerance on element flow distribution is insignificant. By comparing Table 4.2 and Table 4.1, the maximum flow rate per element (X1 and X5) increases 7.0\% (from $468.8 \mathrm{gpm}$ to $501.6 \mathrm{gpm}$ for the nominal case) if the flow redistribution due to burnup is considered.

Table 4.2. Flow Rate Per Element Considering Channel Gap Reduction Due to Burnup

\begin{tabular}{|c|c|c|c|c|c|c|}
\hline \multirow{2}{*}{ Case } & \multicolumn{2}{|c|}{$\begin{array}{c}\text { End channel gap of } \\
\text { X1 and X5 (inch) }\end{array}$} & \multicolumn{4}{|c|}{ Flow rate per element (gpm) } \\
\cline { 2 - 7 } & $\begin{array}{c}\text { Channel } \\
1\end{array}$ & $\begin{array}{c}\text { Channel } \\
24\end{array}$ & $\begin{array}{c}\text { X1a, X5a } \\
\left(0 \text { MWd }^{\mathrm{b}}\right)\end{array}$ & $\begin{array}{c}\text { X3a, X7a } \\
\left(77 \mathrm{MWd}^{\mathrm{b}}\right)\end{array}$ & $\begin{array}{c}\mathrm{X2}^{\mathrm{a}}, \mathrm{X6}^{\mathrm{a}} \\
\left(96 \mathrm{MWd}^{\mathrm{b}}\right)\end{array}$ & $\begin{array}{c}\text { X4a, X8 } \\
\left(180 \mathrm{MWd}^{\mathrm{b}}\right)\end{array}$ \\
\hline Nominal & 0.0955 & 0.0955 & 501.6 & 472.7 & 465.7 & 435.0 \\
\hline Outer nominal & 0.1105 & 0.0805 & 498.2 & 473.9 & 466.8 & 436.1 \\
\hline Outer min & 0.123 & 0.068 & 495.4 & 474.8 & 467.8 & 437.0 \\
\hline Outer max & 0.067 & 0.124 & 508.0 & 470.5 & 463.5 & 433.0 \\
\hline
\end{tabular}

a Refer to Figure 2.1 (a) for element location in the core.

$\mathrm{b}$ Burnup is from MURR LEU equilibrium core $[5,8]$.

\subsubsection{Upper bound of flow rate per element}

The flow rate per element of 468.8 gpm (all fresh elements) or $501.6 \mathrm{gpm}$ (with flow redistribution due to burnup) calculated in the previous sections is based on the prototypic core coolant flow rate of $3750 \mathrm{gpm}$ (shown in Table 3.1). These values of flow rate per element are the best estimate value based on the flow network analysis.

The upper bounding limit/value? of flow rate per element should be determined, and various uncertainties such as primary flow uncertainty and flow disparity between elements should be considered. The normal operating bands of MURR range from $3700 \mathrm{gpm}$ to $3850 \mathrm{gpm}$. The upper bound of $3850 \mathrm{gpm}$ is $2.7 \%$ higher than the prototypic value of $3750 \mathrm{gpm}$. MURR primary coolant flow rate can be measured by both flow transmitters and differential pressure instruments. Although the measurement uncertainty of the flow transmitter is $\pm 0.5 \%$, the most conservative measurement uncertainty for core coolant flow rate from the differential pressure instrument is $\pm 2.0 \%$ based on the input from the reactor operator. These uncertainties were verified by MURR subject matter experts. Therefore, the flow rate through the core could be $4.7 \%$ higher than 3750 gpm given the upper operating limit of 3850 gpm and $2.0 \%$ measurement uncertainty.

In addition to the core flow uncertainty, the element flow disparity should be considered, which is usually defined as the ratio of maximum/minimum flow rate per element to the averaged flow rate per element. As shown in Section 4.2.1, the element flow disparity would be $1.3 \%$ if considering the tolerance of the end channel gap thickness. If taking into account the channel size reduction due to burnup, the element flow disparity would be $7.0 \%$, which is discussed in Section 4.2.2. The measurement of flow disparity between elements is not available. Although the channel flow disparity within one MURR element is assumed to be $\pm 15 \%$ in a previous safety analysis [13], there is no information provided about element flow disparity in that previous work.

By combining the core flow uncertainty of $4.7 \%$, element flow disparity uncertanity of $1.3 \%$ and $7.0 \%$ due to end channel tolerance and burnup-related channel reduction (from Section 4.2.2), respectively, the overall uncertainty of the flow rate per element is $13.5 \%$. These uncertainties are conservatively 
considered here by multiplying the upper bounds $(1.047 \times 1.013 \times 1.07=1.1135)$ instead of using the square root error propagation formula, which would predict $8.5 \%$ combined uncertainty. Note that element flow disparities of $1.3 \%$ (due to end channel tolerance) and $7.0 \%$ (due to burnup-related channel reduction) are estimated using the flow network analysis, and no measurement of such disparity is available. Therefore, it is prudent to allow additional margin to account for the deviation of element flow disparity estimation. As a result, a $20.0 \%$ uncertainty is suggested to envelop the above individual uncertainties and obtain the upper bound of the element flow. This $20 \%$ uncertainty is chosen by engineering judgment to conservatively envelop the core flow uncertainty (4.7\%), element flow disparities due to end channel tolerance $(1.3 \%)$ as well as burnup-related channel reduction (7.0\%). Therefore, the maximum flow rate per element in MURR is expected to be less than $562.5 \mathrm{gpm}$, as shown in Table 4.3.

Table 4.3. Target Test Value of Inlet Flow Rate and Upper Bounding based on $20 \%$ Uncertainty

\begin{tabular}{|c|c|}
\hline \multicolumn{2}{|c|}{ Flow rate per element (gpm) } \\
\hline Nominal & $\begin{array}{c}\text { Upper } \\
\text { bounding }\end{array}$ \\
\hline 468.8 & 562.5 \\
\hline
\end{tabular}

\subsection{Channel flow distribution}

In Section 4.2, the flow rate per element is calculated using the flow network by consolidating all 24 parallel channels of an element. The predicted flow rate per element provides the target test value of the inlet flow rate for the flow test. In this section, the flow network of one element with all 24 channels is used to estimate the velocity of various channels. Although the design parameter of interest in this work is the flow rate per element not the channel coolant velocity, it would still be useful to provide the velocity information as it may be needed in the flow test design (e.g., sensor selection).

The predicted channel flow distribution is shown in Table 4.4. In addition to the case with nominal dimension for all eight elements, the case with different end channel dimensions due to tolerance as well as the case considering the flow channel reduction due to burnup are presented. The Case 'Nominal' in Table 4.4 refers to that end channels (channel 1 and 24) dimension is the nominal value. The Case 'Outer nominal' refers to the case that assumes the outer roller bounding surface touches the pressure vessel wall, while the distance from the outermost plate to the outer roller bounding surface is the nominal value. As a result, the outer end channel gap thickness is smaller ( $0.0805 \mathrm{inch})$, and the inner end channel gap is bigger (0.1105). More details about the end channel dimension are provided in Section 2. If using the nominal size, the channel velocity disparity is up to $3.7 \%$, which is the percentage difference in the flow velocity between the channels with maximum and minimum flow velocity (channel 24 and 6 for the nominal case). For the Case 'Outer nominal', the channel flow disparity can be up to $20.3 \%$ (percentage difference in the flow velocity between channel 1 and 24) because of the reduced channel 24 gap and the increased channel 1 gap. The element average velocity for all fresh elements case is $6.83 \mathrm{~m} / \mathrm{s}$. For the case considering channel reduction due to burnup, the element average velocity is $7.31 \mathrm{~m} / \mathrm{s}$. This section provides the reference velocity of the flow test of MURR, which is around $7 \mathrm{~m} / \mathrm{s}$. 
Table 4.4. Channel Flow Velocity Distribution

\begin{tabular}{|c|c|c|c|c|}
\hline & \multicolumn{2}{|c|}{ Fresh element } & \multicolumn{2}{|c|}{ With burnup } \\
\hline End channel gap Case & Nominal & Outer nominal & Nominal & Outer nominal \\
\hline Channel 1 gap (inch) & 0.0955 & 0.1105 & 0.0955 & 0.1105 \\
\hline Channel 24 gap (inch) & 0.0955 & 0.0805 & 0.0955 & 0.0805 \\
\hline $\begin{array}{l}\text { Flow rate per element } \\
(\mathrm{gpm})\end{array}$ & 468.8 & 465.5 & 501.6 & 498.2 \\
\hline Channel & \multicolumn{4}{|c|}{ Channel flow velocity (m/s) } \\
\hline 1 & 6.87 & 7.63 & 7.43 & 8.16 \\
\hline 2 & 6.77 & 6.85 & 7.32 & 7.33 \\
\hline 3 & 6.78 & 6.86 & 7.33 & 7.34 \\
\hline 4 & 6.79 & 6.87 & 7.34 & 7.36 \\
\hline 5 & 6.80 & 6.88 & 7.35 & 7.37 \\
\hline 6 & 6.76 & 6.84 & 7.31 & 7.32 \\
\hline 7 & 6.77 & 6.85 & 7.32 & 7.33 \\
\hline 8 & 6.77 & 6.86 & 7.33 & 7.34 \\
\hline 9 & 6.78 & 6.86 & 7.33 & 7.35 \\
\hline 10 & 6.79 & 6.87 & 7.34 & 7.35 \\
\hline 11 & 6.79 & 6.88 & 7.35 & 7.36 \\
\hline 12 & 6.80 & 6.88 & 7.35 & 7.36 \\
\hline 13 & 6.80 & 6.89 & 7.36 & 7.37 \\
\hline 14 & 6.81 & 6.89 & 7.36 & 7.37 \\
\hline 15 & 6.81 & 6.89 & 7.37 & 7.38 \\
\hline 16 & 6.81 & 6.90 & 7.37 & 7.38 \\
\hline 17 & 6.82 & 6.90 & 7.37 & 7.39 \\
\hline 18 & 6.82 & 6.91 & 7.38 & 7.39 \\
\hline 19 & 6.82 & 6.91 & 7.38 & 7.39 \\
\hline 20 & 6.88 & 6.96 & 7.44 & 7.45 \\
\hline 21 & 6.88 & 6.96 & 7.44 & 7.45 \\
\hline 22 & 6.88 & 6.97 & 7.44 & 7.46 \\
\hline 23 & 6.88 & 6.97 & 7.45 & 7.46 \\
\hline 24 & 7.01 & 6.34 & 7.58 & 6.79 \\
\hline Average & 6.83 & 6.82 & 7.31 & 7.30 \\
\hline
\end{tabular}




\section{Design Parameters}

The hydraulic design parameters for the MURR LEU fuel element are summarized in Table 5.1. The first primary design parameter is the outer end channel (channel 24) gap thickness (distance between outermost fuel plate to the outer pressure vessel wall), which determines the maximum channel size disparity, and the maximum hydraulic force (induced by pressure differential) on the fuel plate. The nominal value of channel 24 gap thickness is 0.0955 inch and the range due to tolerance is 0.068 inch to 0.124 inch. Compared to the gap thickness of the adjacent channel $23(0.093$ inch), the size disparity is small if assuming a nominal channel gap thickness of 0.0955 inch. The hydraulic pressure differential induced by channel size disparity tends to deform the plate towards the larger channel. Therefore, the hydraulic pressure differential on plate 23 could be either inward or outward, depending on the end channel size. Given the arc-shape of plate 23, the inward force is more limiting (buckling of the plate may occur at sufficiently high pressure), so the minimum channel 24 gap is targeted in the flow test basket design, with the nominal value of 0.0805 inch, and may change from 0.068 inch to 0.094 inch due to the fuel element fabrication tolerance.

The second primary design parameter is flow rate per element. The primary flow rate of the MURR LEU core is $3750 \mathrm{gpm}$, which is distributed into eight fuel elements in the core. The nominal per element flow rate is $468.8 \mathrm{gpm}$, as calculated by dividing the total core flow rate by 8 . The upper bounding of flow rate per element of $562.5 \mathrm{gpm}$ is obtained using the nominal value and the uncertainty factor of 1.2 . This $20.0 \%$ uncertainty is chosen by engineering judgment to conservatively envelope the core flow uncertainty (4.7\%), element flow disparities due to end channel tolerance $(1.3 \%)$ and burnup-related channel reduction (7.0\%).

Temperature influences target test value selection due to the impact of water density on the pressure differential in the test. However, temperature itself is not necessarily a primary design parameter. Until the capability of HMFTF to match the desired temperature range is clarified, water temperature is listed as regime appropriate. Other design parameters, including system pressure and coolant chemistry, are also listed as regime appropriate, but their influence on the flow test results is less significant. However, it is suggested to maintain a similar coolant chemistry property to the prototypic condition during the flow test to avoid any unexpected impact to the MURR LEU fuel element due to the flow test.

The design parameters in this report, including MURR LEU fuel element end channel dimensions and flow rate per element, provide the technical basis for the hydraulic performance evaluation, including the design of a dedicated flow test. 
Table 5.1. MURR LEU Hydraulic Reactor Design Parameters for Flow Test

\begin{tabular}{|c|c|c|c|c|}
\hline Design parameters & Specification & Core condition & $\begin{array}{l}\text { Hydraulic reactor } \\
\text { design parameter }\end{array}$ & Type \\
\hline \multirow{2}{*}{ Flow rate } & Prototypic & $3750 \mathrm{gpm}$ & $468.8 \mathrm{gpm}$ & \multirow{4}{*}{$\begin{array}{c}\text { Primary } \\
\text { design } \\
\text { parameter }\end{array}$} \\
\hline & Maximum & $3850 \mathrm{gpm}$ & $562.5 \mathrm{gpm}^{\mathrm{b}}$ & \\
\hline \multirow{2}{*}{$\begin{array}{l}\text { Outer end channel } \\
\text { gap }\end{array}$} & Nominal & 0.0955 inch & 0.0805 inch & \\
\hline & $\begin{array}{l}\text { Range due to } \\
\text { tolerance }\end{array}$ & 0.068-0.124 inch & $0.068-0.094 \mathrm{inch}$ & \\
\hline Temperature ${ }^{a}$ & - & $49^{\circ} \mathrm{C}-61^{\circ} \mathrm{C}$ & - & \multirow{3}{*}{$\begin{array}{l}\text { Regime } \\
\text { appropriate }\end{array}$} \\
\hline System Pressure & - & 60-66 psig & - & \\
\hline Chemistry & $\mathrm{pH}$ & $5-6$ & - & \\
\hline
\end{tabular}

a Temperature influences target test value selection due to the water density impact on the pressure differential in the test. However, it is not necessarily a primary design parameter. Until the capability of HMFTF to match the desired temperature range is clarified, temperature is listed as regime appropriate.

$\mathrm{b}$ The maximum flow rate per element was calculated using the nominal value and the uncertainty factor of 1.2 , see Section 4.2.3 for details about uncertainty factor. 


\section{Summary}

This work is performed in preparation for the flow test campaign that will be conducted by the USHPRR RC Pillar. The purpose of the hydraulic performance evaluation of the MURR LEU fuel element designed by the RC Pillar is to test a prototypic commercially fabricated LEU fuel element, to determine whether any failure modes are observed or predicted in the fuel element, including significant deformations such as plate bending, twisting, or plate detachment from the side plate under selected safety-basis limits for reactor flow conditions.

Design parameters for hydraulic testing of the LEU fuel element are laid out in this report. These relate to design needs of the reactor and, are therefore, referred to as reactor design parameters since they do not take into account design margins required for the experimental test design and other purposes. Two primary design parameters are provided in this report. First is the geometry of the flow channel, especially the outer end channel gap thickness, which is related to the maximum hydraulic force (induced by pressure differential) on the fuel plate. Second is the flow rate per element, which is $468.8 \mathrm{gpm}$ and can be up to $20 \%$ higher if considering various uncertainties.

The fuel element geometry, including the fuel plate dimensions and the flow channel dimensions, are listed. One key dimension for the MURR flow test is the outer end channel (channel 24) gap thickness (distance between outermost fuel plate to the outer pressure vessel wall), which determines the maximum hydraulic force (induced by pressure differential) on the fuel plate. The nominal value of channel 24 gap thickness is $0.0955 \mathrm{inch}$, and the range due to tolerance is 0.068 inch to $0.124 \mathrm{inch}$. Compared to the gap thickness of the adjacent channel 23 (0.093 inch), the size disparity is small if assuming the nominal channel gap thickness of 0.0955 inch. The hydraulic pressure differential induced by channel size disparity tends to deform the plate towards the larger channel. Therefore, the hydraulic pressure differential on plate 23 could be either inward or outward, depending on the end channel size. Given the arc-shape of plate 23, the inward force is more limiting (buckling of the plate may occur at sufficiently high pressure), so the minimum channel 24 gap is targeted in the flow test basket design, with the nominal value of $0.0805 \mathrm{inch}$, and may change from 0.068 inch to 0.094 inch due to the fuel element fabrication tolerance.

The second primary design parameter is flow rate per element, which is calculated using the flow network method. The effect of end channel gap thickness tolerance on flow rate per element is evaluated, and the results show that varying end channel gap thickness within the tolerance leads to an insignificant (less than 1.3\%) change of the predicted flow rate per element. Therefore, the flow rate per element calculated using the nominal end channel thickness is suggested as the target test value due to simplicity and conservatism, which is $468.8 \mathrm{gpm}$. In addition to the prototypic flow rate per element, uncertainty analysis is performed to estimate the upper bounding for the flow rate per element. The element flow rate disparity induced by channel gap reduction due to different burnup conditions for the elements in the core is evaluated using the flow network. The fuel element burnup of MURR LEU equilibrium core is used as the input for channel gap thickness reduction evaluation, and the element flow rate disparity is $7.0 \%$. The effect of total core flow rate uncertainty is evaluated to be $4.7 \%$, which is determined based on the operating limit of core flow rate $3850 \mathrm{gpm}$ (compared to the prototypic value of $3750 \mathrm{gpm}$ ) and $2.0 \%$ measurement uncertainty. Based on the uncertainty analysis, an uncertainty factor of 1.2 is suggested, which leads to the maximum flow rate per element of $562.5 \mathrm{gpm}$. This $20.0 \%$ uncertainty is chosen by engineering judgment to conservatively envelop the core flow uncertainty (4.7\%), element flow disparities due to end channel tolerance (1.3\%), and burnup-related channel reduction (7.0\%).

University of Missouri Research Reactor LEU Fuel Element Flow Test Conceptual Design - Hydraulic Reactor Design Parameters 
In addition, the nominal coolant temperature at inlet $\left(49^{\circ} \mathrm{C}\right)$ and outlet $\left(61^{\circ} \mathrm{C}\right)$, system pressure $(60$ $66 \mathrm{psig}$ ), and the coolant chemistry specification ( $\mathrm{pH} 5-6)$ are documented as supporting information for the flow test design.

This work provides information that will be used as a part of the design process for hydraulic evaluation, including flow testing a prototypic commercially fabricated LEU fuel element, and will be revised as needed. 


\section{Acknowledgement}

The staff at University of Missouri Research Reactor (MURR ${ }^{\circledR}$ ) is gratefully acknowledged for contributions to reactor conversion, including information of the works referenced. In particular, Das Kutikkad and Nickie Peters, as senior technical staff at MURR, are thanked for their valuable inputs. The authors would like to thank Dr. John Stillman and Dr. Walid Mohamed of Argonne National Laboratory for his valuable comments.

This work was sponsored by the U.S. Department of Energy, Office of Material Management and Minimization in the U.S. National Nuclear Security Administration Office of Defense Nuclear Nonproliferation under Contract DE-AC02-06CH11357. 


\section{References}

[1] J. Stillman, E. Feldman, D. Jaluvka, C. Bojanowski, A. Tentner, T. Heltemes, B. Dionne, M. Kalimullah, J. Stevens, E. Wilson, W. Cowherd, B. Rickman, C. McKibben, K. P. N. Kutikkad and L. Foyto, "Low-Enriched Uranium Conversion Preliminary Safety Analysis Report for the University of Missouri Research Reactor," Submitted to the U.S. Nuclear Regulatory Commission, 2017.

[2] E. Wilson, A. Bergeron, J. Stillman, T. Heltemes, D. Jaluvka and L. Jamison, "US high performance research reactor conversion program: An overview on element design," in Proc. European Research Reactor Conference, Rotterdam, Netherlands, May 14-18, 2017.

[3] J. Stillman, D. Jaluvka and E. Wilson, University of Missouri at Columbia Test Research Training Reactor 4, MURR U-10Mo LEU Fuel Element Assembly and Details, Drawing 2852, University of Missouri Research Reactor (MURR), 2018.

[4] J. Stillman, E. Feldman, S. Pham, D. Yoon, E. Wilson, W. Cowherd, L. Foyto, K. Kutikkad and N. Peters, "Safety Analysis of the Mo-99 Production Upgrade to the University of Missouri Research Reactor (MURR) with Highly-Enriched and Low-Enriched Uranium Fuel," ANL/RTR/TM-18/16, Argonne National Laboratory, Lemont, USA, 2019.

[5] J. Stillman, W. Cowherd, D. Yoon, E. Feldman, K. Kutikkad, N. Peters, J. Gahl, L. P. Foyto and E. Wilson, "Transition Core Planning and Safety Analyses in Support of LEU Fuel Conversion of the University of Missouri Research Reactor (MURR)," ANL/RTR/TM-19/18, Argonne National Laboratory, Lemont, USA, 2020.

[6] "Quality Assurance Requirements for Nuclear Facility Applications," ASME NQA-1b-2008 with 2009 Addenda, American Society of Mechanical Engineers.

[7] "Specification for Low Enriched Uranium Monolithic Fuel Plates," SPC-1635, Rev. 11, Idaho National Laboratory, Idaho Falls, USA, Mar. 2019.

[8] J. A. Stillman, E. E. Feldman, D. Jaluvka, E. H. Wilson, L. P. Foyto, K. Kutikkad, J. C. McKibben and N. J. Peters, "Accident Analyses for Conversion of the University of Missouri Research Reactor (MURR) from Highly-Enriched to Low-Enriched Uranium," ANL/GTRI/TM-14/5, Revision 1, Argonne National Laboratory, Lemont, USA, 2017.

[9] J. Stillman, E. Wilson, D. Yoon, L. F. K. Kutikkad, J. McKibben and N. Peters, "Irradiation Demonstration Element Design Parameters for MURR LEU U-Mo Fuel Conversion," ANL/RTR/TM-18/4 Rev. 1, Argonne National Laboratory, Lemont, USA, March 2020.

[10] "Missouri University Research Reactor (MURR) Safety Analysis Report," MU Project \# 000763, Missouri University Research Reactor, Columbia, USA, 2006.

[11] D. Zigrang and N. Sylvester, "Explicit approximations to the solution of Colebrook's friction factor equation," AIChE Journal, vol. 28, no. 3, pp. 514-515, 1982.

[12] C. F. Colebrook and C. M. White, "Experiments with fluid friction in roughened pipes," Proceedings of the Royal Society of London. Series A-Mathematical and Physical Sciences, vol. 161, no. 906, pp. 367-381, 1937.

[13] E. Feldman, B. Dionne, L. Foyto, M. Kallimullah, K. Kutikkad, J. McKibben, A. Olson, N. Peters, J. Stillman and J. Stevens, "Technical basis in support of the conversion of the University of Missouri Research Reactor (MURR) core from highly enriched to low-enriched uranium steadystate thermal- hydraulic analysis," ANL/RERTR/TM-12-37, Rev. 1, Argonne National Laboratory, Lemont, USA, 2013.

[14] "Nuclear technology branches quarterly report," IN-1083, Idaho Falls, USA, October 1December 31, 1966.

University of Missouri Research Reactor LEU Fuel Element Flow Test Conceptual Design 
[15] L. J. Harrison, "In-Pile Mechanical Failure of MTR Fuel Assemblies," IDO-16862, Idaho Falls, USA, 1963. 



\section{Argonne $\mathbf{A}$}

Nuclear Science \& Engineering Division

Argonne National Laboratory

9700 South Cass Avenue, Bldg. 208

Argonne, IL 60439

www.anl.gov 